\title{
UJI COBA FILTER KERAMIK DENGAN CAMPURAN SEKAM, BEKATUL, SERBUK GERGAJI dan KOLOID PERAK DALAM PENGOLHAN AIR
}

\author{
Slamet Hariyadi, Margono, Didik Sugeng Purwanto
}

\begin{abstract}
Many people commonly are using surface water as the main source for clean and drinking water. Ironically, the quality of surface water decreases from time to time due to domestic and industrial pollution. Earthen pots with colloidal silver applied on their surface created simple coated filters where the silver coating serves as a disinfectant that render the product water ready for consumption.

This is a descriptive pre-experimental research, using one group pretest-posttest design, that is to evaluate water treatment to produce water ready for consumption by analyzing the water quality, before and after treatment with the unit, especially with regard to physical and microbiological parameters according to PERMENKES/NO.492 / MENKES/PER/IV/2010 re: drinking water quality requirements.

Measurements indicated that pottery filter with a mixture of clay-bran $40 \%$ is fastest flow filtration flow filtration, which meant 5 liters of filtrate out in 21 minutes. Meanwhile a mixture clay-wood $20 \%$ with an average flow of (Q) $0.254 \mathrm{lt} / \mathrm{jm}$ was slowest. However clay-rice bran mixture $20 \%$ was the most is stable. Result of microbiological examination on pond water (raw condition) indicated a Co/I MPN Index of $>2400$, and $E$. Coli index of 1600 . After filtration with six pots coated with colloidal silver significant reduction ini microbiological parameter was observed, indicated by MPN. Co/i and $E$. Co/i indices of 0 . Initial (physical) condition of the pond water have indicated no odour, no colour, no taste, and the turbidity level was $11.78 \mathrm{NTU}$, TDS level was $142 \mathrm{mg} / \mathrm{L}$, temperature was $27^{\circ} \mathrm{C}$ and $\mathrm{pH} 5.5$. After passing through six filter pots coated with silver colloids, physicsl parameter i.e. TDS and turbidity decreased, and $\mathrm{pH}$ was normal.

With respect to Permenkes No. 416/1990 and Permenkes No. 492/2010 on requirements for potable water and drinking water respectively, suggestion for follow up research on filter pots coated with colloidal silver pertaining to the chemistry parameters.
\end{abstract} Keywords $\quad \begin{aligned} & \text { clay pot filters, colloidal silver, Coliform, TDS, turbidity, pH, color, temperature, } \\ & \text { odour and taste. }\end{aligned}$

\section{PENDAHULUAN \\ Latar Belakang}

Air permukaan adalah air hujan yang mengalir di permukaan bumi.Pada umumnya air permukaan ini akan mendapat pengotoran/ polusi selama proses mengalir. Air permukaan sering digunakan untuk mencukupi kebutuhan air bersih manusia. Pemanfaatan air permukaan perlu dilakukan pengolahan dalam rangka upaya penyehatan air bersih. Salah satu upaya tersebut adalah melakukanpenyaringan/ filtrasi.Filter merupakan suatu alat yang digunakan untuk menyaring polutan yang tidak dikehendaki. Polutantersebut antara lain adalah bahan padatan, residu organik, dan bahan kimia lainnya.

Tembikar dapat digunakan sebagai filter air untuk menurunkan kandungan bakteri Coliform, logam berat ( $\mathrm{Cu}$ dan $\mathrm{Cr}$ ), warna, kekeruhan, zat organik, besi (Fe), mangan untuk peningkatan kualitas air payau dan air tanah dangkaltelah teruji (Kiuk, 2008 dan Janah, 2009).

\section{Tujuan}

Mengetahui kemampuan filter tembikar dengan koloid perak sebagai media pengolahan air bersih layak konsumsi skala rumah tangga yang memenuhi standar PERMENKES RI No. 492/MENKES/PER/IV/2010.

\section{METODE PENELITIAN \\ Jenis Penelitian}

Pra-eksperimen,denganrancangan one group pretest-posttest design.

\section{Lokasi dan Waktu}

Penelitian ini dilakukan di Bengkel kerja Jurusan Kesehatan Lingkungan POLTEKKES KEMENKES SURABAYAJl. Menur 118-A Surabayapada bulan Juni tahun 2012

\section{Variabel Penelitian}

Variabel Bebas adalah rekayasa filter tembikar dengan bahan tambahan sekam, bekatul, serbuk gergaji.Variabel Terikat adalah kualitas air saringan filter tembikar dengan koloid perak terhadap parameter MPN Coli, bau, warna, TDS, kekeruhan, rasa, suhu.

\section{Metode Analisis Data \\ Datadianalisis secara deskriptif untuk menganalisis efektifitas dan efisiensi filter tembikardengan bahan tambahan koloid perakserta perbedaan komposisinya dalamdalam menurunkan kualitas mikrobiologi dan fisik air.}


HASIL PENELITIAN

Debit Hasil Penyaringan Menurut Variasi

Bahan Campuran (Sekam, Bekatul dan Serbuk Gergaji) Dengan Komposisi 20\%, $40 \%$

Pengukuran debit hasil penyaringan tembikar berpori diukur menggunakan bahan baku aquades 5 liter sesuai volume tembikar. Pengukuran dilakukan setiap $1 / 2$ jam. Hasil pengukuran debit penyaringan dari keenam tembikar berpori dengan variasi bahan tambahan dan komposisi yang berbeda sebagaimana tersaji pada Tabel 1.

Tabel 1

Debit Penyaringan Dari Keenam Tembikar Berpori Dengan Variasi Bahan Tambahan Dan Komposisi Yang Berbeda

\begin{tabular}{|l|c|}
\hline \multicolumn{1}{|c|}{ Jenis Filter } & Rerata Debit (Q) It/jam \\
\hline Tembikar + sekam $40 \%$ & 14,286 \\
\hline Tembikar + sekam $20 \%$ & 0,750 \\
\hline Tembikar + bekatul 40\% & 0,658 \\
\hline Tembikar + bekatul $20 \%$ & 0,138 \\
\hline Tembikar + serbuk gergaji 40\% & 0,656 \\
\hline Tembikar + serbuk gergaji 20\% & 0,254 \\
\hline
\end{tabular}

\section{Identifikasi Efektifitas \& Stabilitas Debit Penyaringan pada Variasi Bahan \& Komposisi Filter} Tembikar

\section{Kecepatan Filtrasi Tembikar Sekam $\mathbf{4 0} \%$}

Proses filtrasi terjadi sangat cepat yaitu 0,238 L/menit sebagaimana ditunjukkan pada Gambar 1

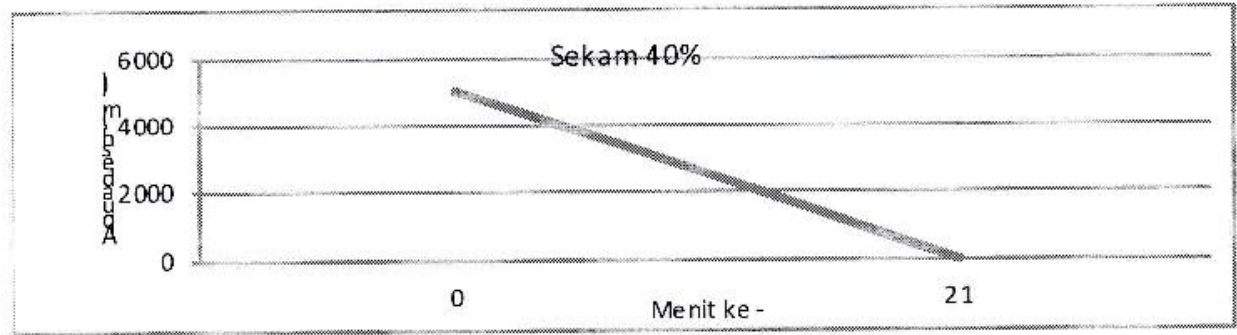

Gambar 1

Grafik Kecepatan Filtrasi Dengan Tembikar Sekam 40\%.

\section{Kecepatan Filtrasi Tembikar Sekam $\mathbf{2 0} \%$}

Berdasarkan Gambar 2 dapat dilihat bahwa kecepatan filtrasi menurun pada jam ke-1 s/d jam ke-1 1/2 $(0,015$ menjadi $0,0136 \mathrm{~L} /$ menit). Setelah itu kecepatan filtrasi konstan pada jam ke-2 $(0,0136$ $\mathrm{L} /$ menit). Terjadi sedikit penurunan pada jam ke-2 $1 / 2(0,0133 \mathrm{~L} /$ menit). Kembali terjadi penurunan cepat pada jam ke-3 dan jam ke- $31 / 2(0,011$ dan 0,0106 L/menit). Kemudian penurunan perlahan pada jam ke-4 (0,01 L/menit). Kembali kecepatan filtrasi konstan pada jam ke-4 1/2 (0,01 L/menit). Terjadi penurunan perlahan pada jam ke-5 (0,009 L/menit).

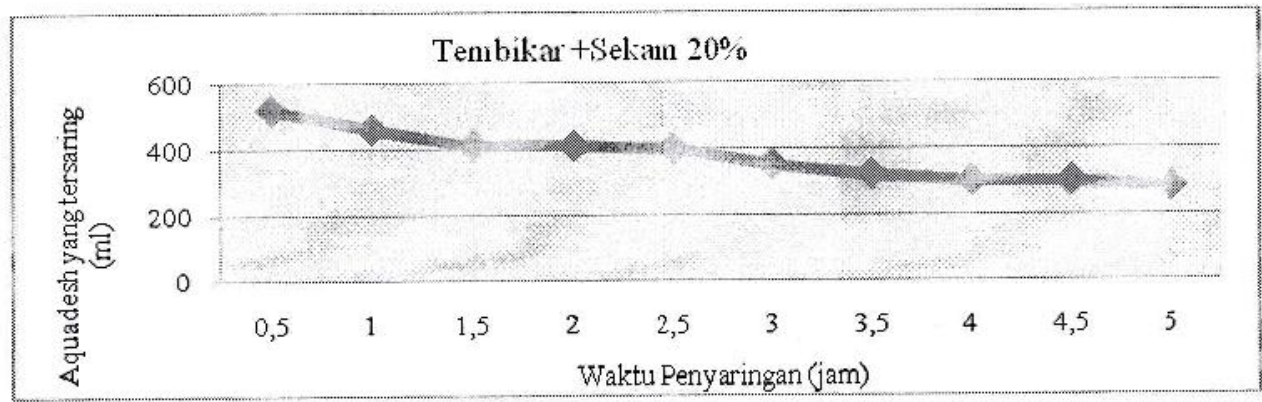

Gambar 2

Grafik Kecepatan Filtrasi Dengan Tembikar Sekam 20\% 


\section{Kecepatan Filtrasi Tembikar Bekatul $\mathbf{4 0} \%$}

Berdasarkan Gambar 3 dapat dilihat kecepatan filtrasi menurun drastis pada jam ke-1 $(0,0133$ $\mathrm{L} /$ menit). Setelah itu terjadi sedikit penurunan pada jam ke-1 1/2 (0,013 L/menit). Kecepatan filtrasi kembali konstan pada jam ke-2 $(0,013 \mathrm{~L} /$ menit). Terjadi lagi penurunan cepat pada jam ke-2 1/2 $(0,0106 \mathrm{~L} /$ menit). Terjadi sedikit penurunan jam ke-3 $(0,0103 \mathrm{~L} /$ menit). Ada penurunan cepat jam ke-3 1/2 (0,009 L/menit). Penurunan perlahan pada jam ke-4 (0,0083 L/menit). Setelah itu penurunan stabil dengan rata-rata $10 \mathrm{ml}$ pada jam ke-4 1/2 dan ke-5 (0,008 dan 0,0076 L/menit).

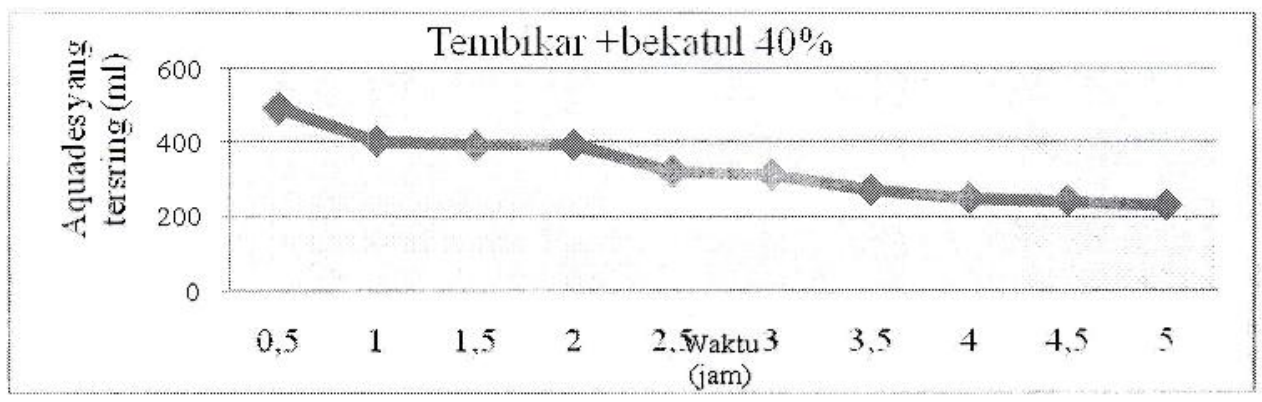

Gambar 3

Grafik Kecepatan Filtrasi Dengan Tembikar Bekatul 40\%.

4. Kecepatan Filtrasi Tembikar Bekatul $20 \%$

Berdasarkan gambar 4.5 dapat dilihat kecepatan filtrasi menurun secara stabil dengan rata-rata $10 \mathrm{ml}$ mulai jam ke-1, $1 \frac{1 / 2}{2}$ dan ke-2 $(0,006,0,0056$ dan $0,0053 \mathrm{~L} /$ menit). Kecepatan filtrasi kembali konstan pada jam ke-2 1/2 (0,0053 L/menit). Terjadi penurunan sedikit jam ke-3 $(0,005$ $\mathrm{L} /$ menit), lalu kecepatan filtrasi konstan sampai dengan jam ke-4 1/2 (0,005 L/menit). Penurunan terjadi kembali pada jam ke-5 (0,0043 L/menit).

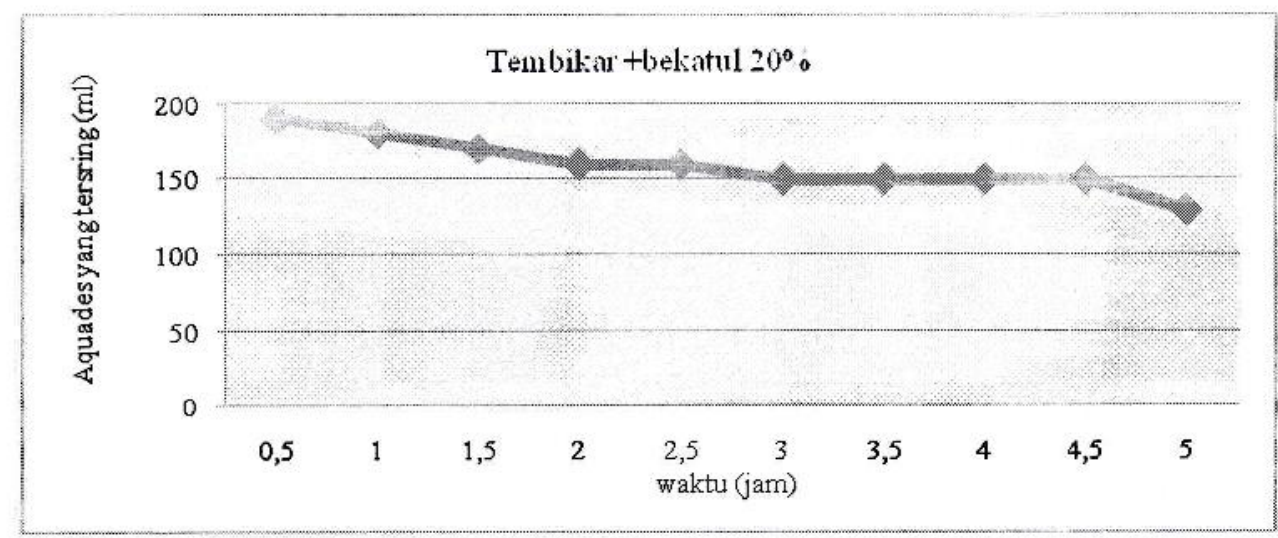

Gambar 4

Grafik Kecepatan Filtrasi Dengan Tembikar Bekatul 20\%

\section{Kecepatan Filtrasi Tembikar Kayu $\mathbf{4 0} \%$}

Berdasarkan gambar 5 dapat dilihat kecepatan filtrasi menurun cepat pada jam ke-1 $(0,0126$ $\mathrm{L} /$ menit). Terjadi lagi sedikit penurunan pada jam ke-1 1/2 (0,012 L/menit). Setelah itu konstan pada jam ke-2 $(0,012 \mathrm{~L} /$ menit). Terjadi kembali penurunan cepat pada jam ke-2 $1 / 2(0,0103$ L/menit). Kecepatan filtrasi konstan pada jam ke-3 (0,0103 L/menit). Kecepatan filtrasi turun perlahan pada jam ke-3 $1 / 2(0,0096 \mathrm{~L} /$ menit), lalu kembali konstan pada jam ke-4 (0,0096 L/menit). Terjadi sedikit penurunan pada jam ke-4 1/2 (0,0093 L/menit), selanjutnya kecepatan filtrasi konstan pada jam ke-5 (0,0093 L/menit) 


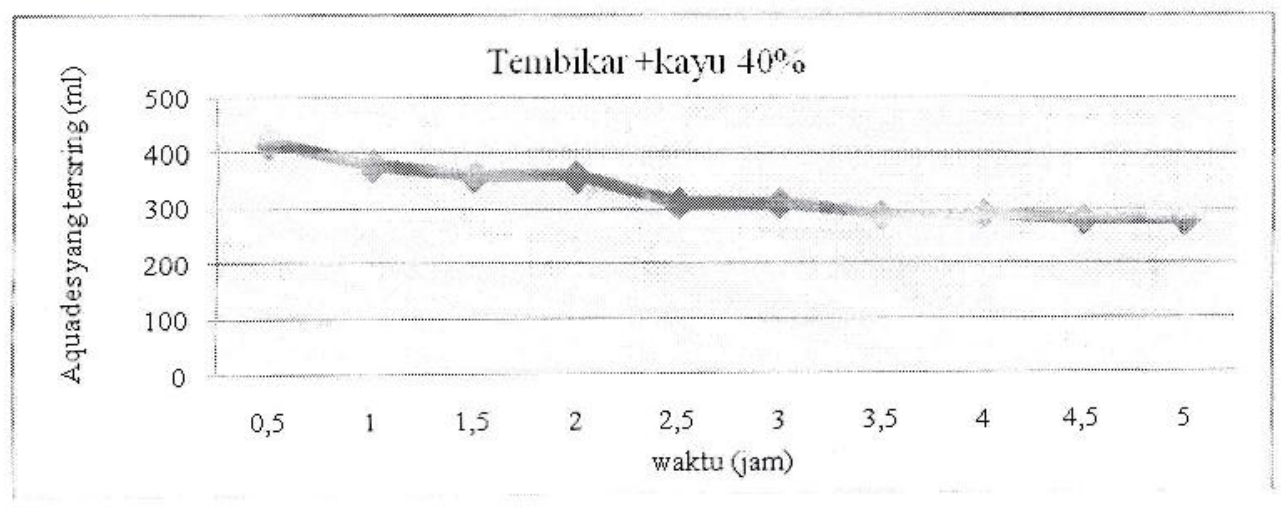

Gambar 5

Grafik Kecepatan Filtrasi Dengan Tembikar Kayu 40\%

\section{Kecepatan Filtrasi Tembikar Kayu $\mathbf{2 0} \%$}

Berdasarkan gambar 4.7 dapat dilihat kecepatan filtrasi menurun pada jam ke-1(0,0046 L/menit). Setelah itu terjadi penurunan sedikit pada jam ke-1 1/2 dan jam ke-2 (0,0043 dan 0,004 L/menit), selanjutnya kecepatan filtrasi konstan sampai dengan jam ke-4 1/2 (0,004 L/menit). Kembali terjadi penurunan sedikit pada jam ke-5(0,0036 L/menit).

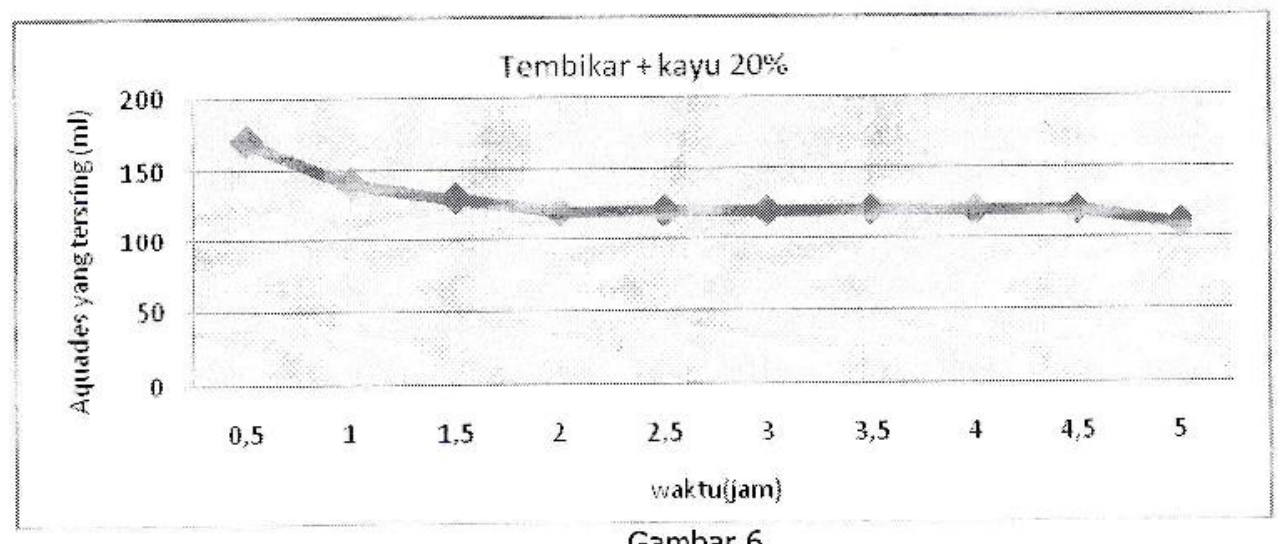

Grafik Kecepatan Filtrasi Dengan Tembikar Kayu 20\%

Hasil Uji Laboratorium Filter Tembikar + Koloid Perak dengan Parameter Mikrobiologi (MPN. Coli) pada Air Kolam

Hasil pengukuran kualitas bakteriologi air kolam sebagai air baku adalah nilai MPN. Coliformsebesar $>2400$ MPN/ $100 \mathrm{ml}$ sampelsedangkan untuk E. Coli adalah $1600 \mathrm{MPN} / 100 \mathrm{ml}$ sam:pel. Hasil penurunan nilai $M P N$. Colidan E. colioleh filter tembikar + koloid perak sebagaimana disajikan pada tabel 2 berikut

Tabel 2

Hasil Analisa Penurunan Mpn. Coli Dan E. Coli

Oleh Filter Tembikar + Koloid Perak

\begin{tabular}{|c|c|c|c|c|c|c|c|}
\hline \multirow{3}{*}{ No. } & \multirow{3}{*}{$\begin{array}{l}\text { Parameter } \\
\text { Mikrobiologi }\end{array}$} & \multicolumn{6}{|c|}{ Bahan Tambahan } \\
\hline & & \multicolumn{2}{|c|}{ Sekam } & \multicolumn{2}{|c|}{ Bekatul } & \multicolumn{2}{|c|}{ Serbuk Gergaji } \\
\hline & & $40 \%$ & $20 \%$ & $40 \%$ & $20 \%$ & $40 \%$ & $20 \%$ \\
\hline \multirow[t]{3}{*}{1.} & \multicolumn{7}{|c|}{ MPN. Coli (MPN/ $100 \mathrm{ml}$ sampel) } \\
\hline & Konsentrasi & 13 & 0 & 0 & 0 & 0 & 0 \\
\hline & Penurunan (\%) & 99,46 & 100 & 100 & 100 & 100 & 100 \\
\hline \multirow[t]{3}{*}{2.} & \multicolumn{7}{|c|}{ E. Coli (MPN/ $100 \mathrm{ml}$ sampel) } \\
\hline & Konsentrasi & 5 & 0 & 0 & 0 & 0 & 0 \\
\hline & Penurunan (\%) & 99,68 & 100 & 100 & 100 & 100 & 100 \\
\hline
\end{tabular}


Hasil Uji Laboratorium Filter Tembikar + Koloid Perak dengan Parameter Fisika pada Air Kolam

Hasil pengukuran kualitas fisika air kolam sebagai air baku adalah sebagaimana ditunjukkan pada Tabel 3 berikut.

Tabel 3.

Hasil Analisa Kualitas Fisik Awal Air Kolam

\begin{tabular}{|c|c|c|c|}
\hline No. & $\begin{array}{c}\text { Parameter } \\
\text { Fisika }\end{array}$ & Satuan & Hasil Analisa air sampel \\
\hline 1. & Bau & $\#$ & Tidak berbau \\
\hline 2. & Jumlah zat padat terlarut (TDS) & $\mathrm{mg} / \mathrm{L}$ & 142 \\
\hline 3. & Kekerutian & Skala NTU & 11,78 \\
\hline 4. & Rasa & $\#$ & Tidak berasa \\
\hline 5. & Suhu & ${ }^{\circ} \mathrm{C}$ & 27 \\
\hline 6. & $\mathrm{pH}$ & $\#$ & 5,5 \\
\hline 7. & Warna & TCU & Tidak berwarna \\
\hline
\end{tabular}

Hasil uji laboratorium air kolam melalui penyaringan tembikar berpori dilabur koloid perak terhadap parameter fisika tersaji pada Tabel 4 berikut.

Tabel 4

Hasil Analisa Fisika Penurunan Tds Dan Kekeruhan Oleh Filter Tembikar + Koloid Perak

\begin{tabular}{|c|c|c|c|c|c|c|c|}
\hline \multirow{2}{*}{ No. } & \multirow{2}{*}{ Parameter Fisika } & \multicolumn{7}{c|}{ Bahan Tambahan } \\
\cline { 3 - 8 } & & \multicolumn{2}{|c|}{ Sekam } & \multicolumn{2}{c|}{ Bekatul } & Serbuk Gergaji \\
\cline { 3 - 8 } & $40 \%$ & $20 \%$ & $40 \%$ & $20 \%$ & $40 \%$ & $20 \%$ \\
\hline 1. & Bau & TB & TB & TB & TB & TB & TB \\
\hline 2. & Rasa & TB & TB & TB & TB & TB & TB \\
\hline 3. & Warna (TCU) & TB & TB & TB & TB & TB & TB \\
\hline 4. & $\mathrm{pH}$ & 7 & 7 & 7,1 & 7 & 7 & 7,2 \\
\hline 5. & Suhu ( $\left.{ }^{0} \mathrm{C}\right)$ & 29 & 29 & 28 & 28,5 & 29 & 28 \\
\hline 6. & \multicolumn{8}{|c|}{ Jumlah zat padat terlarut (TDS) mg/L } \\
\cline { 2 - 8 } & Konsentrasi & 149 & 99 & 96 & 95 & 114 & 97 \\
\cline { 2 - 8 } & Penurunan (\%) & 4,92 & 30,28 & 32,39 & 33,09 & 19,71 & 31,69 \\
\hline 7. & \multicolumn{8}{|c|}{ Kekeruhan (Skala NTU) } & 1,86 \\
\cline { 2 - 8 } & Konsentrasi & 3,27 & 1,69 & 1,86 & 1,8 & 3,56 & 1,64 \\
\cline { 2 - 8 } & Penurunan (\%) & 72,24 & 85,65 & 84,21 & 84,71 & 69,77 & 86,07 \\
\hline
\end{tabular}

\section{Kesimpulan}

Sekam paidi menimbulkan porositas yang lebih besar. Dengan demikian semakin banyak penambahan bahan pencampur, semakin besar juga pori yang dihasilkan sehingga turut memperbesar kelolosan air terhadap media filter ini.

Debit penyaringan Filter tembikar menurut bahan campuran (sekam,bekatul,serbuk gergaji) dengan komposisi $20 \%, 40 \%$ yang paling efektif/stabil adalah filter tembikar campuran bekatul $20 \%$.

Koloid perak sebagai desinfektan terbukti ampuh membunuh dan menghambat perkembangbiakan bakteri khususnya MPN. Coli pada air kolam telah memenuhi persyaratan air bersih juga air minum (Permenkes no. 416 dan 492).
Hasil uji laboratorium awal air kolam termasuk kategori air bersih untuk parameter fisika sesuai Permenkes no. 416. Setelah dilakukan pengolahan dari enam filter tembikar dilabur koloid perak menunjukkan bahwa air baku tersebut memenuhi syarat air bersih bahkan untuk minum sesuai Permenkes no. 492.

\section{Saran}

Perlu adanya kontrol untuk mengetahui efektifitas filter tembikar tanpa perlakuan koloid perak. Pemeriksaan kualitas air kolam dengan parameter kimia untuk penelitian selanjutnya.

Mengingat hasil penelitian untuk memenuhi kebutuhan air bersih, pendayagunaan filter tembikar dilabur koloid perak sudah signifikan dalam menurunkan bakteri Coliform, TDS, kekeruhan, warna, pH.Masyarakat menengah ke bawah bisa mengaplikasikan sendiri di rumah. 


\section{DAFTAR PUSTAKA}

Alaert, G dan Sumestri, Sri S., "Metoda Penelitian Air", Usaha Nasional, Surabaya, 1984.

Fardiaz, Srikandi. 1993. Mikrobiologi Pangan I. PT. Gramedia Pustaka Utama. Jakarta.

Hariady, Sigit. 1998. Metodologi Analisa Kualitas Air. Bogor. Institut Pertanian Bogor.

Janah, Ni'matul dan Karnaningrum, Nieke, 2009. Penggunaan Filter Tembikar untuk Meningkatkan Kualitas Air Tanah Dangkal di Kelurahan Pogot Surabaya. Laporan Tugas Akhir (S1). Jurusan Teknik Lingkungan-FTSP ITS Surabaya.

Kiuk, J.I, 2008. Penyediaan Air Bersih di Wilayah Pesisir dengan Menggunakan Filter Tembikar Studi Kasus Pantai Kenjeran Surabaya. Laporan Tugas Akhir (S1). Jurusan Teknik Lingkungan-FTSP ITS Surabaya.

Sutrisno, Totok, 2006. Teknologi Penyediaan Air Bersih. Rineka Cipta. Jakarta. 